Article

\title{
Interactive Correlation Environment (ICE) - A Statistical Web Tool for Data Collinearity Analysis
}

\author{
Igor Ogashawara ${ }^{1, *}$, Marcelo P. Curtarelli ${ }^{1}$, Arley F. Souza ${ }^{2}$, Pétala B. Augusto-Silva ${ }^{1}$, \\ Enner H. Alcântara ${ }^{3}$ and José L. Stech ${ }^{1}$
}

1 Remote Sensing Division, National Institute for Space Research (INPE), Avenida dos Astronautas, 1758, São José dos Campos, SP 12227-010, Brazil; E-Mails: mpedroso@dsr.inpe.br (M.P.C.); petala@dsr.inpe.br (P.B.A.-S.); stech@dsr.inpe.br (J.L.S.)

2 ETEP Faculdades, Avenida Barão Rio Branco, 882, São José dos Campos, SP 12242-800, Brazil; E-Mail: arley.souza@etep.edu.br

3 Cartography Department, State University of São Paulo, Rua Roberto Simonsen, 305, Presidente Prudente, SP 19060-900, Brazil; E-Mail: enner@fct.unesp.br

* Author to whom correspondence should be addressed; E-Mail: igoroga@gmail.com; Tel.: +55-12-3208-6484.

Received: 12 February 2014; in revised form: 27 February 2014 / Accepted: 31 March 2014 / Published: 4 April 2014

\begin{abstract}
Web tools for statistical investigation with an interactive and friendly interface enable users without programming knowledge to conduct their analyses. We develop an Interactive Correlation Environment (ICE) in an open access platform to perform spectral collinearity analysis for biogeochemical activity retrieval. We evaluate its performance on different browsers and applied it to retrieve chlorophyll- $a$ (chl- $a$ ) concentration in a tropical reservoir. The use of ICE to retrieve water chl- $a$ concentration got a Root Mean Square Error (RMSE) lower than 7\% for seasonal datasets, enhancing ICE's ability to adapt it within season. An RMSE of $17 \%$ was found for the mixed dataset with a large range of chl- $a$ concentrations. We conclude that the use of ICE is recommended, due to its quick response, easily manipulation, high accuracy, and empirical adaptation to seasonal variability. Its use is enhanced by the development of hyperspectral sensors, which allow the identification of several biogeochemical components, such as chl- $a$, phycocyanin (PC), soil salinity, soil types, leaf nitrogen, and leaf chl- $a$ concentration.
\end{abstract}

Keywords: 2D correlation plot; web tool; correlation; bio-optical; chlorophyll; band ratio 


\section{Introduction}

Statistical techniques, such as correlation, have been used for different analyses, such as sequence comparison [1], time series [2], and data collinearity [3]. Spectral collinearity analyses have been used by remote sensing scientists to retrieve biogeochemical activity from spectral measures using in situ, airborne or orbital hyperspectral sensors. Remote sensing scientists have been investigating the use of spectral collinearity analyses to identify and map several biogeochemical components, such as aquatic chlorophyll- $a$ (chl- $a$ ) [4], phycocyanin (PC) [5], soil salinity [6], soil types [7], leaf nitrogen, and leaf chl- $a$ concentration [8].

The application of two dimensional (2D) correlation plots for remote sensing studies of water quality generally makes use of a band ratio as it suppresses the specular reflection from water under wavy conditions [9]. Oki [10] analyzed the reason of good performance of band ratios on the estimation of chl- $a$ concentration and concluded that band selection is a crucial step in the process. Ha et al. [11], using the Moderate Resolution Imaging Spectroradiometer (MODIS)/Terra, proposed a model based on the ratio of green and blue band reflectance to also estimate chl- $a$ in a the Tien Yen Bay in Northern Vietnam. On the other hand, Gitelson et al. [12] recommended for chl-a bio-optical models in inland waters the use of red and near infrared (NIR) relationship because of the high interference of other constituents on the blue channel. Ogashawara et al. [13] analyzed the performance of several reflectance-based bio-optical models for the estimation of PC. Among the analyzed algorithms, three published band ratios were analyzed: Schalles and Yacobi [14] $\left(\mathrm{R}_{\mathrm{rs}}(650) / \mathrm{R}_{\mathrm{rs}}(624)\right)$, Simis et al. [15] $\left(\mathrm{R}_{\mathrm{rs}}(709) / \mathrm{R}_{\mathrm{rs}}(620)\right)$ and Mishra et al. [16] $\left(\mathrm{R}_{\mathrm{rs}}(700) / \mathrm{R}_{\mathrm{rs}}(600)\right)$. Results from Ogashawara et al. [13] showed that for high concentrations of PC Simis et al. [15] and Mishra et al. [16] band ratios showed better performance, however for low PC concentrations, locally tuned band ratios have the best performance. This finding enhances Oki's [10] idea of the importance of spectral bands selection for the bio-optical modeling of biogeochemical constituents.

Therefore, 2D correlation plots are an important tool for band selection because of its capability to cover all possible band ratios. Its importance is enhanced by the new hyperspectral sensors that have been developed in recent years, as well as future sensors. Despite these advantages of using this statistical technique as tool, the use of 2D color correlation plots for several remote sensing applications is still restricted due to the lack of a statistical tools to easily calculate them.

The development of web tools has been extensively reported in the last decade due to the increasing exposure of the World Wide Web as a ubiquitous communication medium [17]. These web tools have been developed for different applications to support their clients with a friendly interface. They also have reduced technological barriers and made it easier and less costly to produce information to support policy makers with management decisions, wherever and whenever they may need it [18]. The use of web tools is also enhanced because of the use of the World Wide Web, which can reduce some of the technical problems associated with the hardware and software issues (e.g., the need for special hardware configuration on the client machines) [19]. Therefore, these tools have been widely used by planners, managers, analysts, decision-makers within local government, society, and other interested parties. However, few web applications have scientists as their clients.

In this study, we present a web tool to support scientists to perform spectral analysis of biogeochemical components. This web tool could be applied to different remote sensing targets, such 
as water components, soil, forest, and native vegetation management. Our primary aim was to develop an interactive web tool to create, visualize and download a 2D color correlation plot. It was also part of our goal to provide this web tool in an open access platform to support users' decisions and analysis. We also provided a case study using the web tool to quantify chl- $a$ in a tropical hydroelectric reservoir in Brazil.

\section{Tool Development}

Interactive Correlation Environment (ICE) was developed using Hyper Text Markup Language 5 (HTML5) and Javascript and it was also designed to run using only the personal browser's resources. Moreover, it was also designed to not transfer and process users' data in a server. Thus, all data entered in the web tool will not be accessed by any other person. The procedures to use ICE (Interactive Correlation Environment) start by inserting a dependent variable. This procedure will allow the user to enter the matrix of independent variables. After entering the data, the code will automatically calculate the following matrices: correlation coefficient $(r)$; absolute correlation coefficient $(A b s(r))$; and determination coefficient $\left(R^{2}\right)$. The last procedure is entering the title and labels of the $\mathrm{X}$ and $\mathrm{Y}$ axis.

\subsection{The Web Tool}

ICE is an open access web tool, which can be accessed on the following web address: http://www.dsr.inpe.br/hidrosfera/ice. Figure 1 shows the layout of ICE, which is primarily in English, but it also has a Portuguese version by clicking on the Brazilian flag. The web tool was created in just one web page and it is based on three steps, which are only available if you finish the previous step correctly. Therefore, the users were not expected to upload datasets in text format. Datasets can be uploaded via copy and paste into provided boxes from any text or spreadsheet format. Usable separator characters are explained in the online instructions.

Figure 1. The open access web tool layout.

ICE - Interactive Correlation Environment
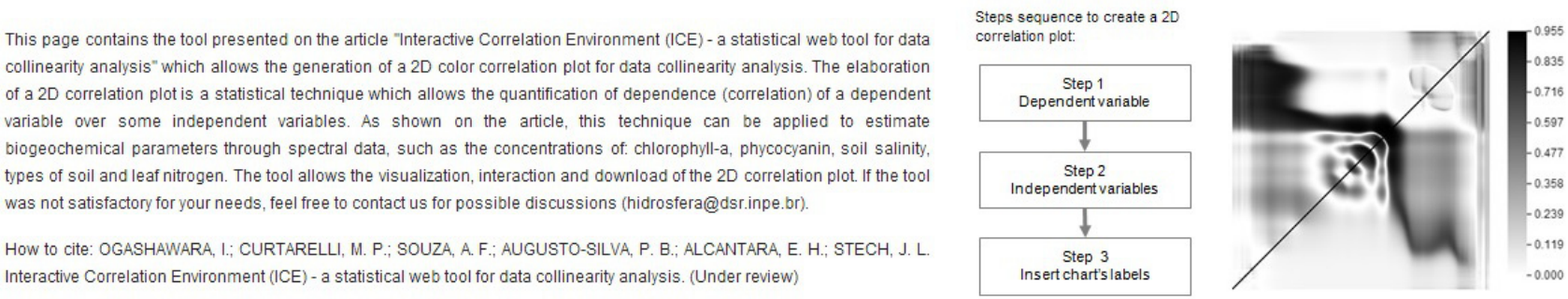


\subsection{ICE's Functions}

The interactivity of the web tool is based on several functions developed to improve the interpretation of the 2D correlation plot. The first function allows the user to choose the statistical estimator; options are: $A b s(r), r$ and $R^{2}$ (Figure 2A). It is also possible to choose the color palette of the $2 \mathrm{D}$ correlation plot (Figure 2B). The palette function improves the visualization and interpretation of the 2D correlation plot. A filtering function (Figure 2C) was implemented to set the minimum and maximum values of correlation estimators, enabling visualization of the chosen range. An export function (Figure 2D) was implemented to allow the download of the 2D correlation plot in three different sizes $(25 \%, 50 \%$, and $100 \%)$ in a Portable Network Graphics (PNG) format. The last function is the pixel location information of the mouse cursor (Figure 2E). It retrieves the information from the $2 \mathrm{D}$ correlation plot's pixel where the cursor is located.

Figure 2. ICE interactive functions: (A) estimator function; (B) Color palette function; (C) Filtering function; (D) Export function; (E) Pixel location function.

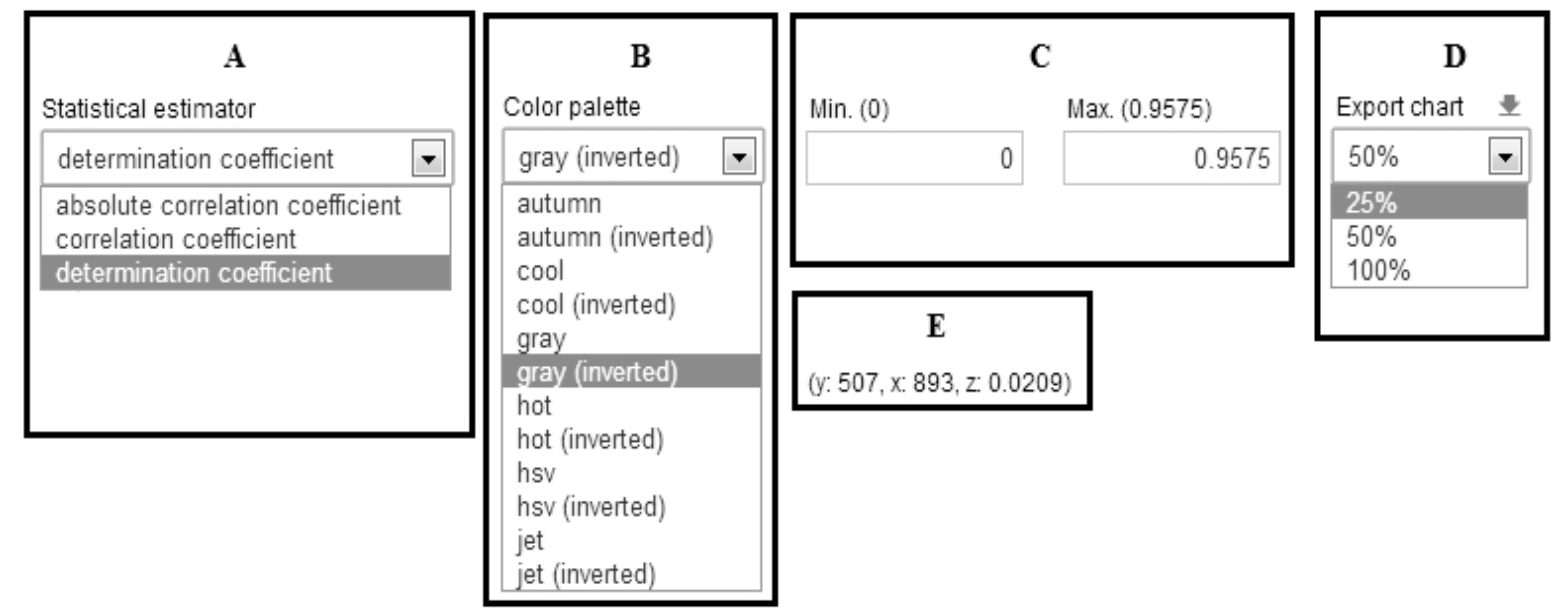

\subsection{Performance of the Web Tool}

A performance analysis of processing time using different datasets was conducted using four different browsers: Google Chrome (v. 33.0.1750.154 m), Internet Explorer (v. 11.0.9600.16521), Mozilla Firefox (v. 15.0.1), and Safari (v. 5.1.7). The datasets used in this analysis were composed of collected in situ data and two synthetic datasets with a large range of data (490,000 and 1,000,000 values) to explore each browser's capacity. It was performed using a personal computer with Windows 7 (Microsoft Corporation, Redmond, Washington) in an Intel i7 processor with 16 GB of RAM memory.

\section{Case Study}

\subsection{Study Site}

The study area (Figure 3) of this research was a hydroelectric reservoir-the Funil Reservoir $\left(22^{\circ} 32^{\prime} \mathrm{S}\right.$ and $\left.44^{\circ} 45^{\prime} \mathrm{W}\right)$. The reservoir has a $16,800 \mathrm{~km}^{2}$ catchment area, surface of $40 \mathrm{~km}^{2}$, mean depth of $22 \mathrm{~m}$, maximum depth of $70 \mathrm{~m}$ and total volume of $8.9 \times 10^{9} \mathrm{~m}^{3}$. The retention time varies from 10 
to 50 days according to the season of the year [20]. It drains water from the hydrographic basin of Paraíba do Sul river, in Southeast Brazil, and it is located between the cities of Itatiaia and Resende in the state of Rio de Janeiro. This hydrographic basin connects three economically important Brazilian states including Minas Gerais, Rio de Janeiro, and São Paulo.

Figure 3. Location of Funil Reservoir, Itatiaia, Rio de Janeiro, Brazil.

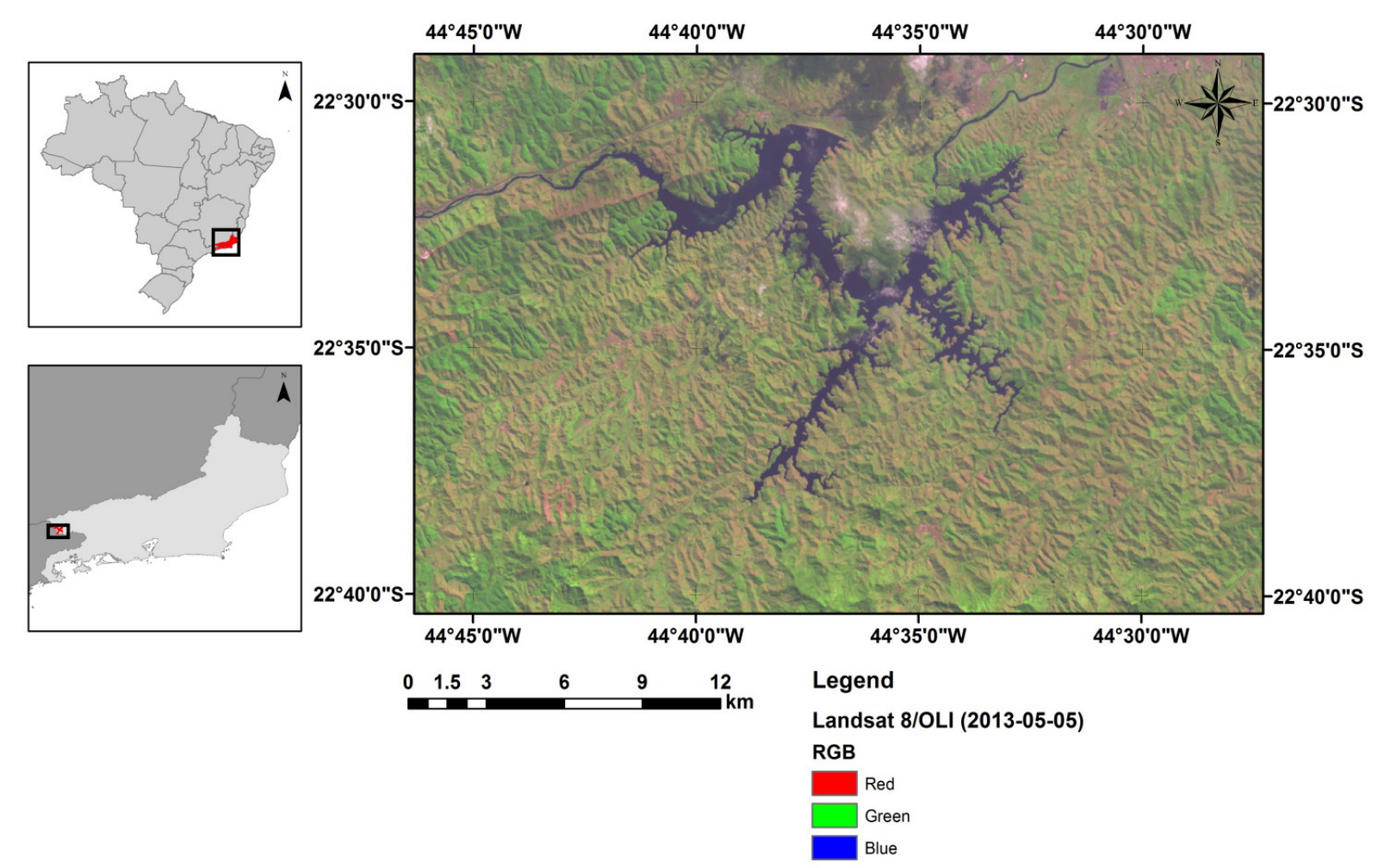

Funil Reservoir was constructed during the late 1960s with the purpose of being an important hydroelectric power generation source. However, Branco et al. [21] computed that the Funil reservoir also serves as the primary source of water for domestic supply (drinking), irrigation, industrial self-supply systems, and aquaculture. Despite this, the reservoir receives waste from one of the main Brazilian industrial areas with a large range of industries: 19 chemical, 26 siderurgical and metallurgical, five electric and electronic, one petrochemical, three paper and cellulose, and few others, such as food and textile industries [22].

As consequence of the draining of all these industrial waste the income of nutrients has been increasing. Because of this, the enhancement of the eutrophication process has been observed in recent decades [21]. Thus, the Funil Reservoir showed to be a favorable environment for the development of Harmful Algal Blooms. Ferrão-Filho et al. [23] analyzed Funil Reservoir from June 2002, to March 2006, and concluded that Funil is a cyanobacterial dominated reservoir. The authors found three main species of cyanobacterias, which are potentially producers of microcystins (a hepatotoxin) and saxitoxins (a neurotoxin): Anabaena circinalis, Cylindrospermopsis raciborskii and Microcystis spp. According to Ferrão-Filho et al. [23] the concentration of these cyanotoxins were also found on zooplankton cells (Daphnia pulex) showing that they had been contaminated. Thus, the monitoring of water quality in the Funil Reservoir is important because of its multiple uses for human needs. 


\subsection{Data Collection}

\subsubsection{Remote Sensing Reflectance}

Field radiometric measurements in the Funil Reservoir, Brazil, were acquired during three field campaigns: 20-22 May 2012; 02-04 September 2012; and 2-5 April 2013. Radiance and irradiance measurements were carried out using the RAMSES hyperspectral radiometers (TriOS GmbH, Oldenburg, Germany). These sensors take measurements in the visible and NIR ranges of the spectrum (360-900 nm) with $3.3 \mathrm{~nm}$ spectral resolution (0.3 nm accuracy). Remote sensing reflectance from subsurface $\left(\mathrm{r}_{\mathrm{rs}}\right)$ was estimated according to Equation (1) and linearly interpolated for a spectral resolution of $1 \mathrm{~nm}$.

$$
r_{r s}=\frac{L_{u}}{E_{d}}
$$

Two sensors were used, irradiance and radiance sensors, acquiring data simultaneously. The irradiance sensor was centered at nominal (excluding effects of wave motion) viewing zenith angle $\left(\theta_{\mathrm{v}}\right)$ of $90^{\circ}$ pointed upward (for downwelling irradiance, $\mathrm{E}_{\mathrm{d}}$ ) direction. A radiance sensor was pointed downward to measure the upwelling radiance $\left(\mathrm{L}_{\mathrm{u}}\right)$. These two measures were collected above and below the air-water interface, $(1 \mathrm{~m}, 2 \mathrm{~m}$, and $3 \mathrm{~m})$ the water surface.

\subsubsection{Chl- $a$}

For chl-a analysis, water samples were collected from the subsurface, approximately $10 \mathrm{~cm}$ below the water surface, and were kept at cool temperatures until delivery to the laboratory for analysis. The method of chl- $a$ analysis consisted of filtering the collected samples using GF/F filters (Whatman, $0.7 \mu \mathrm{m}$ pore size) and then extracting the samples from the filters using $90 \%$ acetone and measuring the absorbance in a Varian Cary 50 Conc UV-VIS spectrophotometer (Agilent Technologies, Santa Clara, CA, USA) [24]. Concentrations of chl- $a$ were calculated from the spectrophotometric absorbance data using the equations from Lorenzen [25].

\subsection{Spectral Band Selection}

For preliminary analysis ICE was used to generate $2 \mathrm{D}$ color correlation plots of $\mathrm{R}^{2}$. The $2 \mathrm{D}$ correlation plots were obtained by sequential regression of all possible $r_{\mathrm{rs}}$ band ratios $(302,500)$ in the range 350-900 nm vs. chl- $a$ concentration (Figure 4). The straight diagonal lines indicate 1:1 ratio. To easily visualize the $2 \mathrm{D}$ correlation plot, it was set a minimum $\mathrm{R}^{2}$ of 0.9 using the filtering function implemented in the web tool (Figure 5). Through this process it was possible to determine the most sensitive band ratio for the chl- $a$ estimation for each dataset using the filter and pixel information functions. Thus, the filtering process makes it easier to pick out important band ratios since it highlights the better-correlated band ratios. The best band ratio varied among the datasets due to the difference on the sampling period since data collection was performed during low and high flow seasons. 
Figure 4. ICE's 2D color correlation plot of $\mathrm{R}^{2}$ for (A) FM12; (B) FS12; (C) FA13.

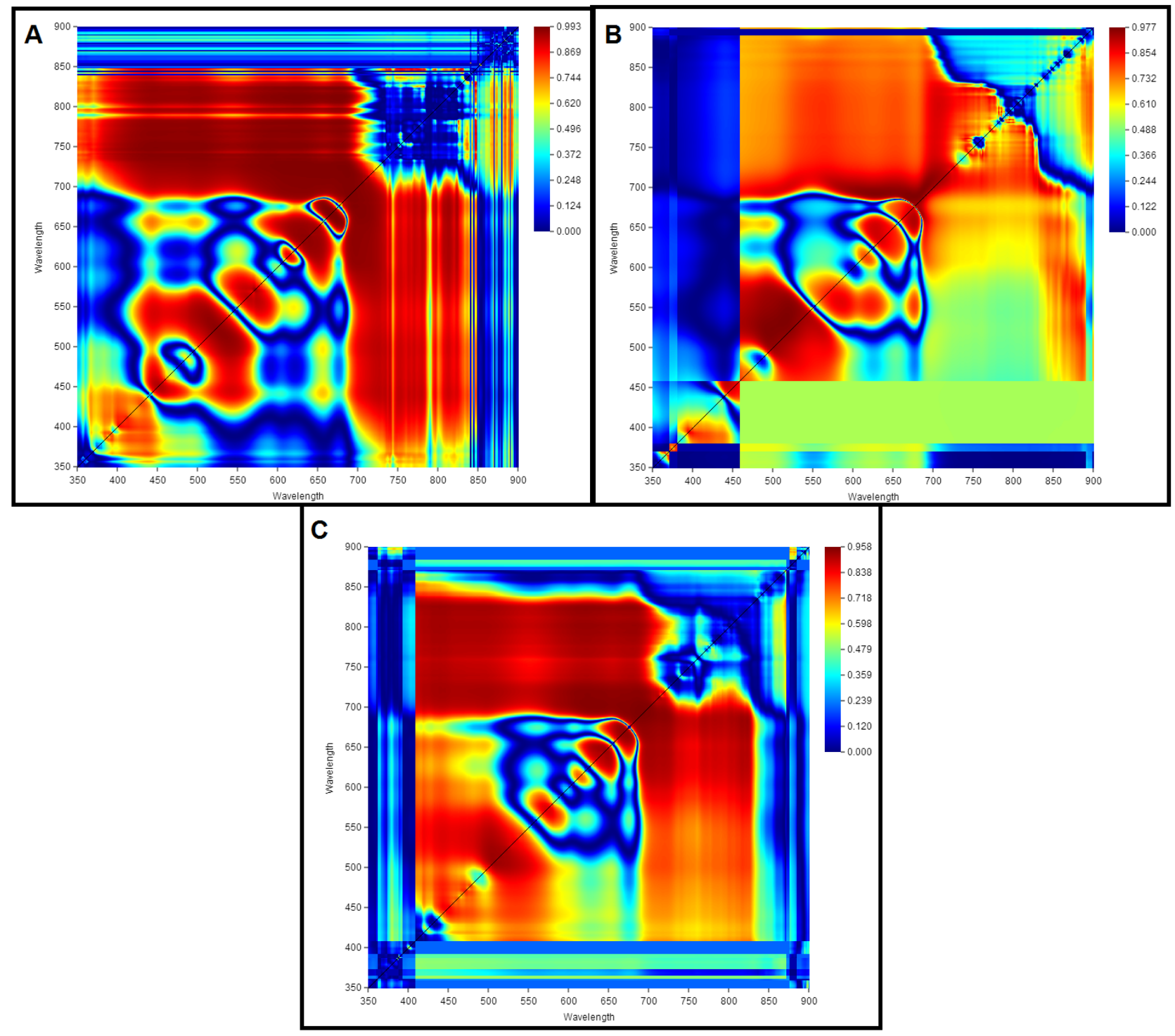

Although the use of Red and NIR relation is recommended for chl- $a$ bio-optical models in inland waters [12], ICE showed that the best correlations were found using different relations for each dataset. For the dataset of the campaign conducted at May 2012 (FM12), the 661/673 was the best band ratio. On the other hand, for September 2012 (FS12) and April 2013 (FA13) the best band ratios were 534/515 and 695/688, respectively.

From Figure 5 it is possible to observe that on a $2 \mathrm{D}$ color correlation plot B (for September) it is not possible to observe the influence of blue spectral bands as observed on plots A (May) and C (April). The explanation for the influence of blue spectral bands on these datasets occurs because of the low concentration of chl- $a$, which allows the influence of other aquatic constituents, such as Total Suspended Solids (TSS) and Colored Dissolved Organic Matter (CDOM). Both of these constituents have strong influence on blue spectral region. Therefore in waters with low concentration of chl- $a$ (mixed or complex waters) the influence in the blue region is higher. 
Figure 5. ICE's 2D color correlation plot after the filtering tool of $R^{2}$ for (A) FM12; (B) FS12; (C) FA13.

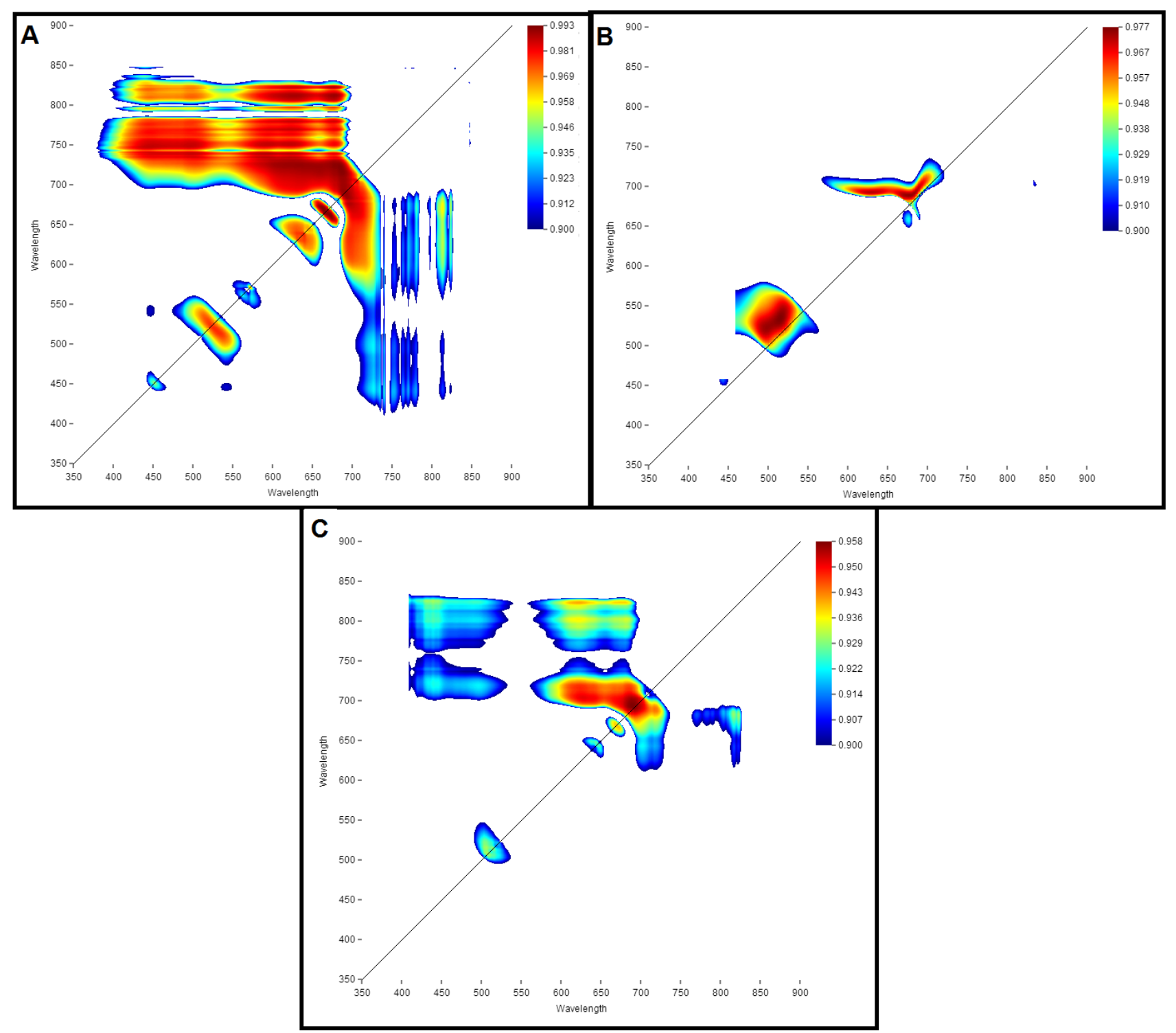

\subsection{Calibration and Validation}

We calibrated all three band ratios to each dataset; we also calibrated two bio-optical models (that we will later refer to as Red-NIR band ratios) proposed in the literature, 748/667 (GI08) [12] and 709/665 (MO09) [26], to compare to the results of ICE's band ratios calibrations. We performed a cross-calibration among the datasets, applying their calibrations for each model to its correspondent band ratio. The result of this cross-calibration is the estimated chl-a concentration for each model.

Validations of the application of each calibration on the other two datasets were conducted using scatter plots and two error estimators: the Root Mean Square Error (RMSE) and Normalized Root Mean Square Error (NRMSE), which were calculated according to the equations on Table 1. 
Table 1. Error estimators used in this study.

\begin{tabular}{cc}
\hline Estimator & Formulas \\
\hline RMSE & $R M S E=\sqrt{\frac{1}{n} \sum_{i=1}^{n}\left(y_{i}-x_{i}\right)^{2}}$ \\
NRMSE $(\%)$ & $N R M S E(\%)=\frac{R M S E}{y_{i, \max }-y_{i, \min }}$ \\
\hline
\end{tabular}

Note: $y_{i}$ and $x_{i}$ are the measured and predicted chl-a concentration, respectively. In $i^{\text {th }}$ sample; $y_{i, \max }$ and $y_{i, \min }$ are the maximum and minimum chl-a concentrations, respectively.

\section{Results and Discussion}

\subsection{Browsers' Performance}

Table 2 shows the result of the performance analysis of ICE using its processing time as an parameter of evaluation; shaded areas highlight the best performances (in seconds). As described on Section 2.3, two synthetic datasets with random values were created to test the browsers' performance using ICE with great amount of data. A dependent variable with 100 random values was tested with an independent variable with 700 (R700) and 1000 (RA1K) random values. NS values on the table means that the browser could not support running of the web tool.

Table 2. Performance of browsers' time response in seconds.

\begin{tabular}{cccccc}
\hline Dataset & Size & Chrome & Firefox & IE & Safari \\
\hline FM12 & $(541 \times 10)$ & 0.8 & 0.8 & 1.3 & 2.6 \\
FS12 & $(541 \times 10)$ & 0.8 & 0.8 & 1.3 & 2.6 \\
FA13 & $(541 \times 16)$ & 1.1 & 1.2 & 2 & 3.3 \\
R700 & $(700 \times 100)$ & 5.2 & 13.1 & NS & 32.7 \\
RA1K & $(1000 \times 100)$ & NS & 39.4 & NS & 89.1 \\
\hline
\end{tabular}

Two browsers (Firefox and Safari) were able to perform the 2D color correlation plot for all datasets and all four web browsers, when they supported the processes, were all able to run in under a minute and a half. Therefore although Google Chrome got the best performance among the four smallest datasets, it was not able to run the $2 \mathrm{D}$ color correlation plot on the largest dataset. This fact shows that the important information of Table 2 is that some web browsers do not support certain processes. Thus, Internet Explorer showed the worst performance among all browsers tested as it could not perform ICE for the two synthetic datasets.

It was observed that ICE provides a quick response for processing the $2 \mathrm{D}$ correlation plot. The simple and interactive interface allows users with no knowledge on computer programming to process their data. However, ICE's performance is limited by the browsers' processing capability. As shown in Table 2, each browser has its own capability, which justifies the difference in time and performance among the datasets. Nevertheless, these problems may be overcome up new and/or updated web browsing software. 


\subsection{Cross-Calibration}

Table 3 shows the $\mathrm{R}^{2}$, slope and intercept values for the calibrations for each model in each dataset. As expected, ICE's band ratios for each dataset showed the highest $\mathrm{R}^{2}$ among the others. The highest $\mathrm{R}^{2}$ for FM12, FS12, and FA13 datasets were found on ICE selected band ratios with a $\mathrm{R}^{2}$ of $0.99,0.97$, and 0.96 for the datasets, respectively.

Table 3. $\mathrm{R}^{2}$ table of band ratios values $v s$. chl- $a$ concentrations.

\begin{tabular}{c|ccc|ccc|ccc}
\hline & \multicolumn{3}{|c|}{ FM12 } & \multicolumn{3}{c|}{ FS12 } & \multicolumn{3}{c}{ FA13 } \\
\hline Ratio & $\boldsymbol{R}^{\mathbf{2}}$ & Slope & Intercept & $\boldsymbol{R}^{\mathbf{2}}$ & Slope & Intercept & $\boldsymbol{R}^{\mathbf{2}}$ & Slope & Intercept \\
\hline $748 / 667$ & 0.96 & 304.42 & -10.11 & 0.77 & 107.31 & 36.30 & 0.90 & 599.26 & -22.21 \\
$709 / 665$ & 0.99 & 85.91 & -10.17 & 0.89 & 32.098 & 6.67 & 0.95 & 78.00 & -37.04 \\
$661 / 673$ & 0.99 & 121.83 & -136.87 & 0.93 & 35.014 & -16.46 & 0.93 & 293.91 & -332.77 \\
$534 / 515$ & 0.97 & 100.18 & -123.14 & 0.97 & 202.31 & -280.20 & 0.90 & 191.49 & -284.49 \\
$695 / 688$ & 0.99 & 72.21 & -61.76 & 0.97 & 190.22 & -189.41 & 0.96 & 156.92 & -147.09 \\
\hline
\end{tabular}

Calibration results for FM12 dataset showed high $\mathrm{R}^{2}$ for almost all the band ratios; the lowest $\mathrm{R}^{2}$ was produced by $748 / 667$ and the highest was produced by $661 / 673$ with values of 0.966 and 0.992 respectively. For the FS12 dataset, calibrations showed lower $\mathrm{R}^{2}$ compared to the previous dataset with the lowest $\mathrm{R}^{2}$ of 0.775 for $748 / 667$ and the highest $\mathrm{R}^{2}$ of 0.976 for $534 / 515$. For the FA13 dataset calibrations showed that the range of $\mathrm{R}^{2}$ values started from 0.901 for $748 / 667$ to 0.957 for $695 / 688$.

ICE's band ratios showed better performance on calibration than the Red-NIR band ratios [12,25]. Although ICE's band selection used in each dataset is different, the selected band ratio for each dataset is related to the chl- $a$ concentration, which changed through the seasons. This change affects mainly the reflectance peaks of chl- $a$ on Green and NIR channels. Figure 6 shows the $\mathrm{r}_{\mathrm{rs}}$ spectra for the three datasets where the difference on the green (around $550 \mathrm{~nm}$ ) and NIR (around $700 \mathrm{~nm}$ ) spectral channels can be observed.

The average chl- $a$ concentration for FM12 was $7.67 \mu \mathrm{g} / \mathrm{L}$ while for FS12 and FA13 the average chl- $a$ concentrations were 90.89 and $19.49 \mu \mathrm{g} / \mathrm{L}$ respectively. From Figure 5, a high correlation was observed for Blue-Green algorithms. However, as described by Gitelson et al. [12] the absorption by non-algal particles, CDOM, and water, as well as backscattering by all particulate matter have strong overlapping absorption features in the blue spectral region, which help make the blue reflectance an unreliable indicator of the concentration of chl- $a$ in inland and coastal aquatic systems.

\subsection{Validation}

Table 4 shows the NRMSE (\%) for estimation of chl- $a$ from the cross calibration among the datasets; shaded areas indicate the lowest NRMSE. The lowest NRMSE was found by applying FA13 calibration on FS12 with an NRMSE of 9.60 and $8.36 \%$ for the 534/515 and 695/688 band ratios, respectively. Figure 7 shows the validation plots for the application of FA13 calibration on the FS12 dataset. Scatter plots agree with NRMSE values and also show a distribution near to the one to one line for the $534 / 515$ and $695 / 688$ band ratios. 
Figure 6. $r_{\text {rs }}$ spectra for the three datasets: FM12 $(n=10), \operatorname{FS} 12(n=10)$ and FA13 $(n=16)$.
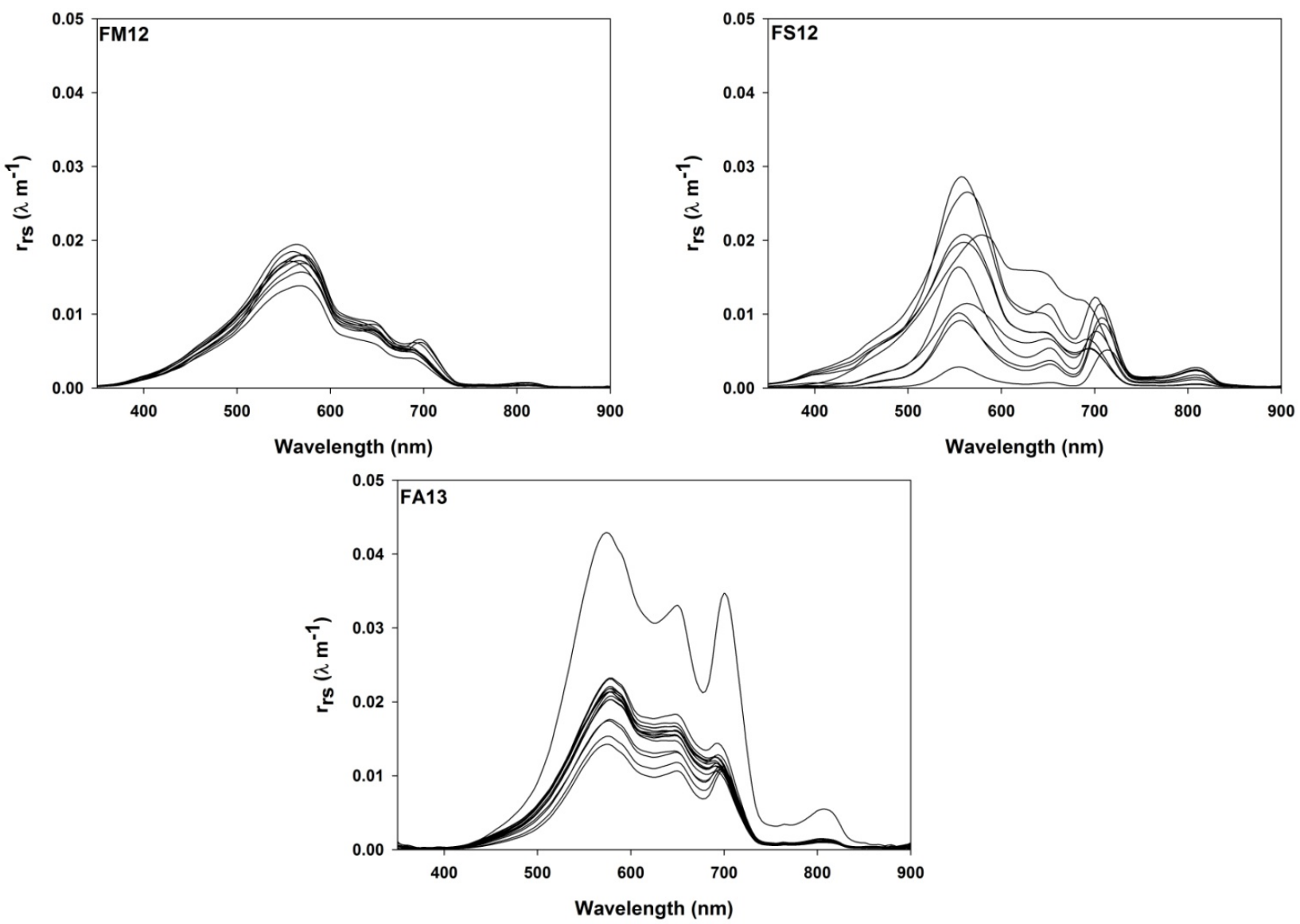

Figure 8 shows the validation plots for the application of FS12 calibration on FM12 dataset. Scatter plots agree with NRMSE values in Table 4, showing points far from the one to one line.

Table 4. Normalized Root Mean Square Error (NRMSE) (\%) of measured and estimated chl- $a$ concentration from the cross calibration.

\begin{tabular}{ccccccc}
\hline Calibration & \multicolumn{2}{c}{ FM12 } & \multicolumn{2}{c}{ FS12 } & \multicolumn{2}{c}{ FA13 } \\
\hline Dataset & FS12 & FA13 & FM12 & FA13 & FM12 & FS12 \\
\hline $748 / 667$ & $57.97 \%$ & $24.75 \%$ & $228.66 \%$ & $56.98 \%$ & $46.54 \%$ & $147.40 \%$ \\
$709 / 665$ & $67.12 \%$ & $68.56 \%$ & $42.51 \%$ & $28.97 \%$ & $185.99 \%$ & $52.15 \%$ \\
$661 / 673$ & $92.55 \%$ & $28.98 \%$ & $115.98 \%$ & $30.23 \%$ & $71.43 \%$ & $282.69 \%$ \\
$534 / 515$ & $19.81 \%$ & $38.22 \%$ & $158.41 \%$ & $45.89 \%$ & $276.51 \%$ & $9.60 \%$ \\
$695 / 688$ & $25.84 \%$ & $19.98 \%$ & $107.39 \%$ & $17.15 \%$ & $46.63 \%$ & $8.36 \%$ \\
\hline
\end{tabular}

The use of ICE to select the best-correlated band ratios to chl- $a$ concentration showed low NRMSE and high $\mathrm{R}^{2}$ for most of the cases. Table 3 showed that, for all datasets, using ICE's selected band ratios produced the highest $\mathrm{R}^{2}$. However, Table 4 showed that 748/667 and 709/665 produced the lowest NRMSE (42.51\% for the FS12 calibration and 46.54\% for the FA13 calibration) for the low chl- $a$ concentrations dataset (FM12). On the other hand, for medium and high chl- $a$ concentrations datasets (FA13 and FS12) ICE's band ratios produced the lowest NRMSE $(<20 \%$ for both datasets for all the calibrations). Among ICE's band ratios, the 695/688 showed good performance on NRMSE because this band ratio was produced from an intermediary dataset, which could estimate better 
responses than the other two. We also observed that the Funil Reservoir water constituents vary during the year, because of the changes in the land use and cover around the reservoir, which affect its water quality.

Figure 7. Scatter plots for validation of band ratio performance for FS12 dataset using FA13 Calibration.
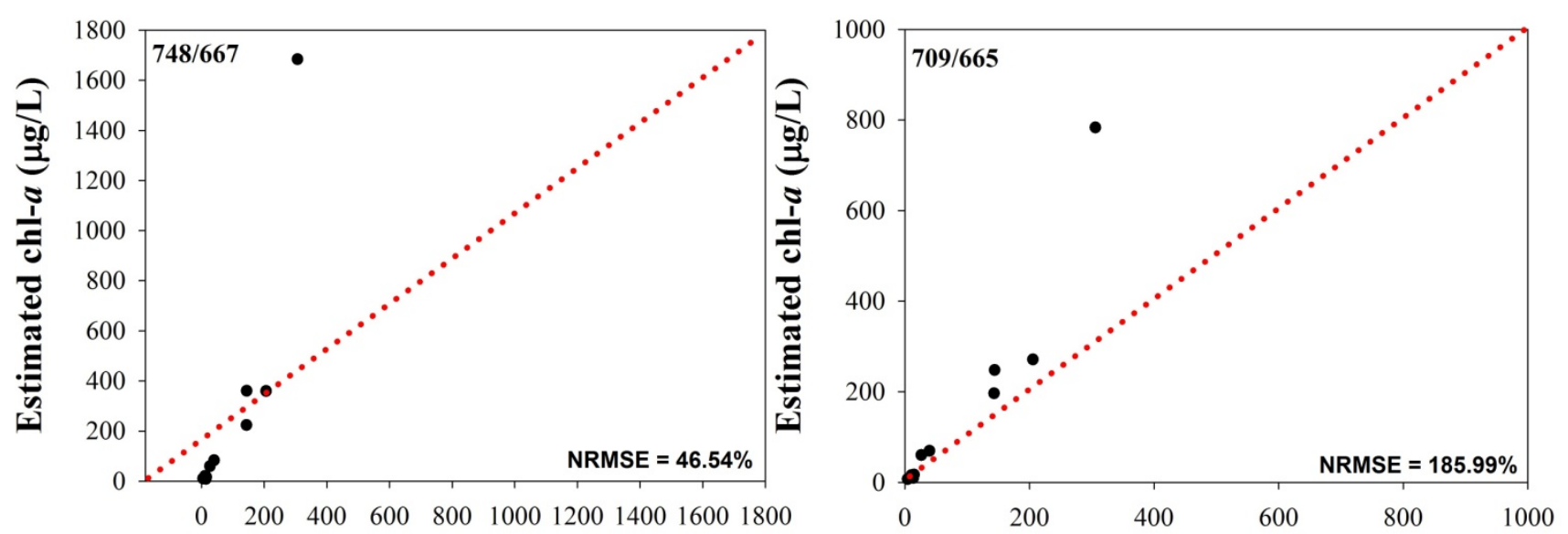

Measured chl- $a(\mu \mathrm{g} / \mathrm{L})$

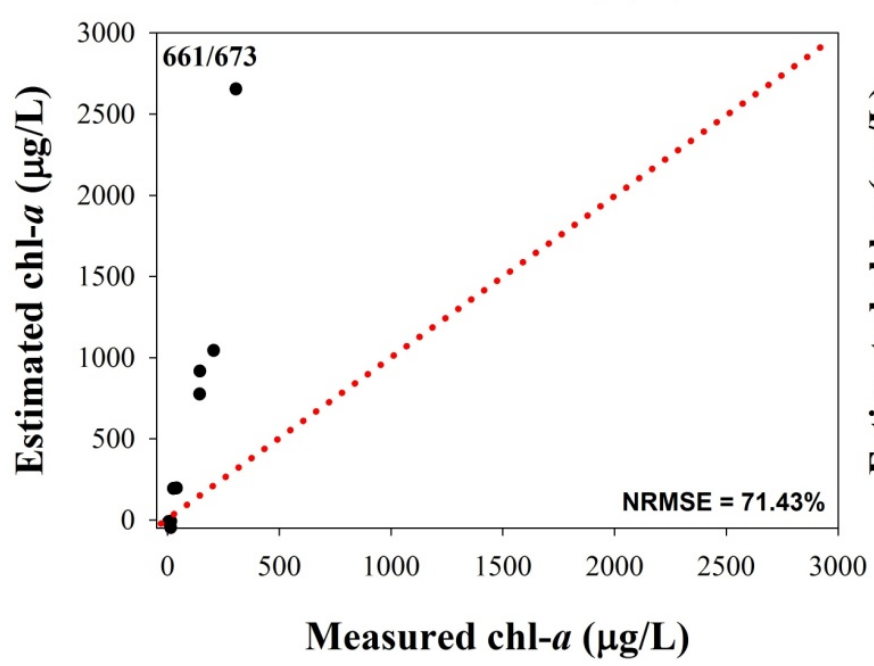

Measured chl- $a(\mu \mathrm{g} / \mathrm{L})$
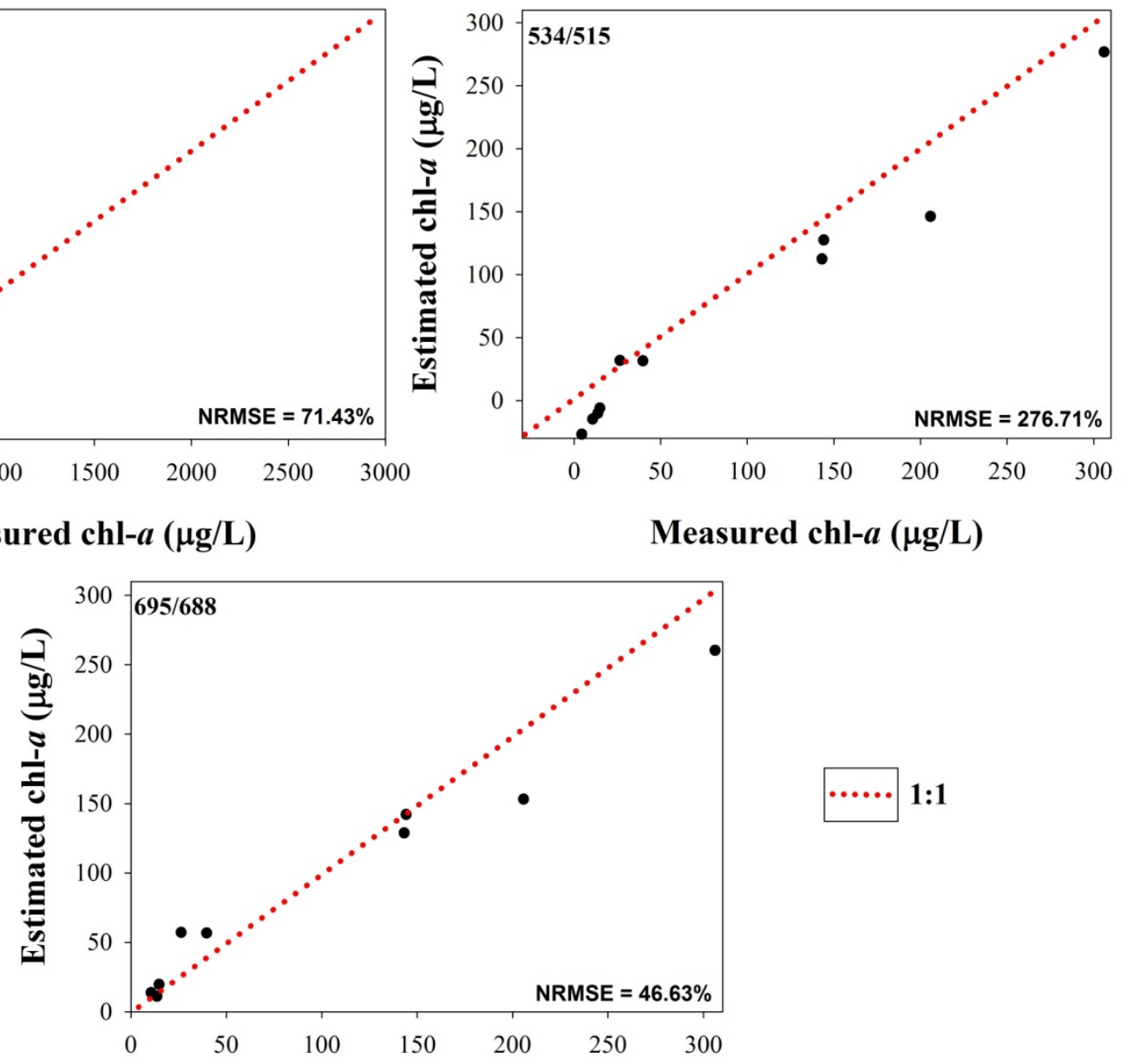

Measured chl- $a(\mu \mathrm{g} / \mathrm{L})$ 
Figure 8. Scatter plots for validation of band ratio performance for FM12 dataset using FS12 Calibration.

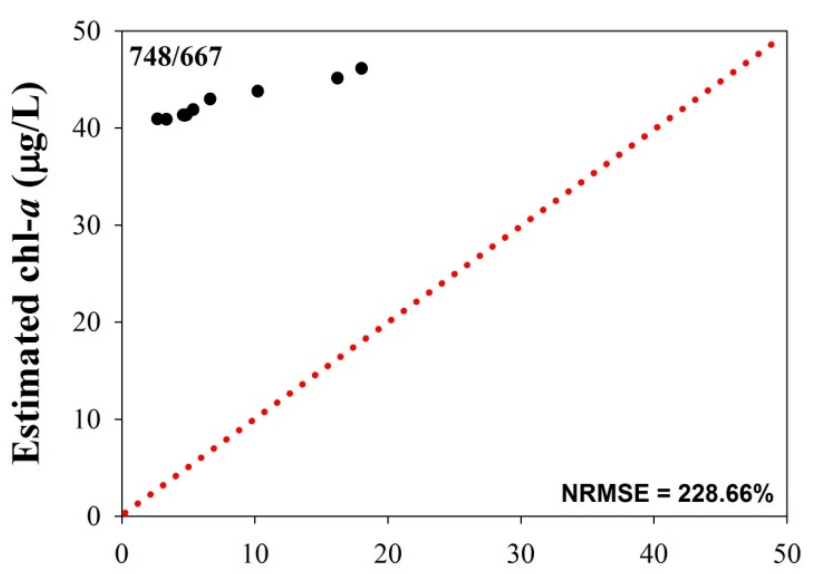

Measured chl- $a(\mu \mathrm{g} / \mathrm{L})$

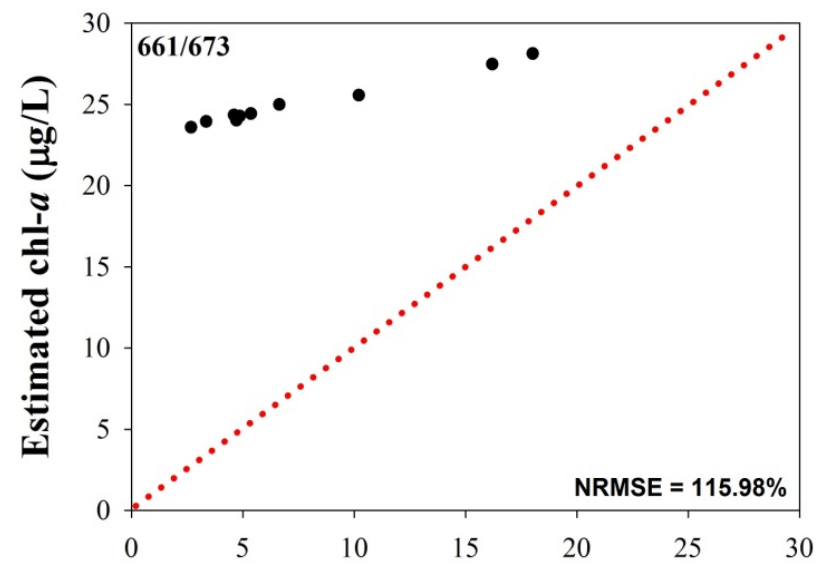

Measured chl- $a(\mu \mathrm{g} / \mathrm{L})$

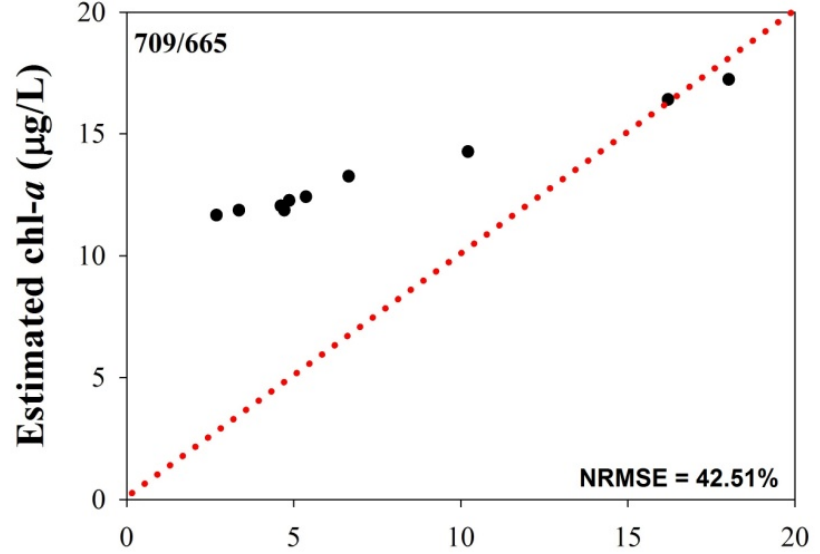

Measured chl- $a(\mu \mathrm{g} / \mathrm{L})$

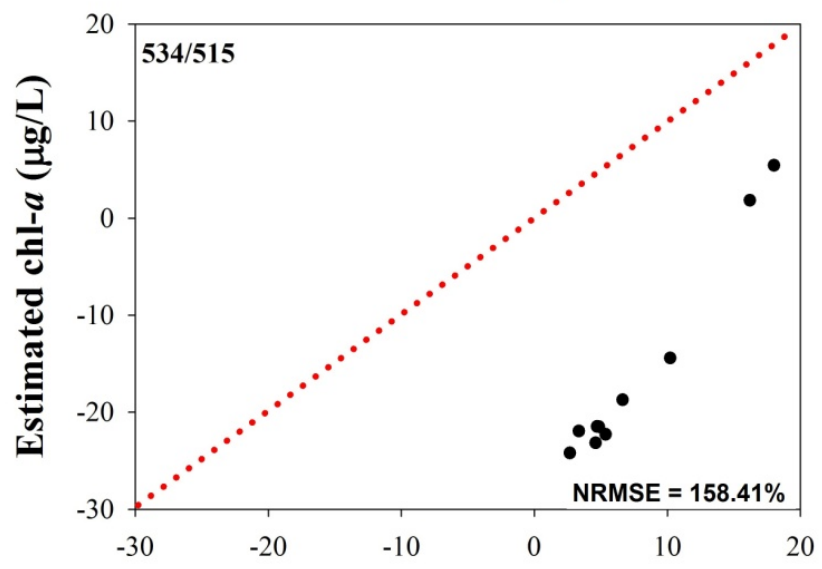

Measured chl-a $(\mu \mathrm{g} / \mathrm{L})$

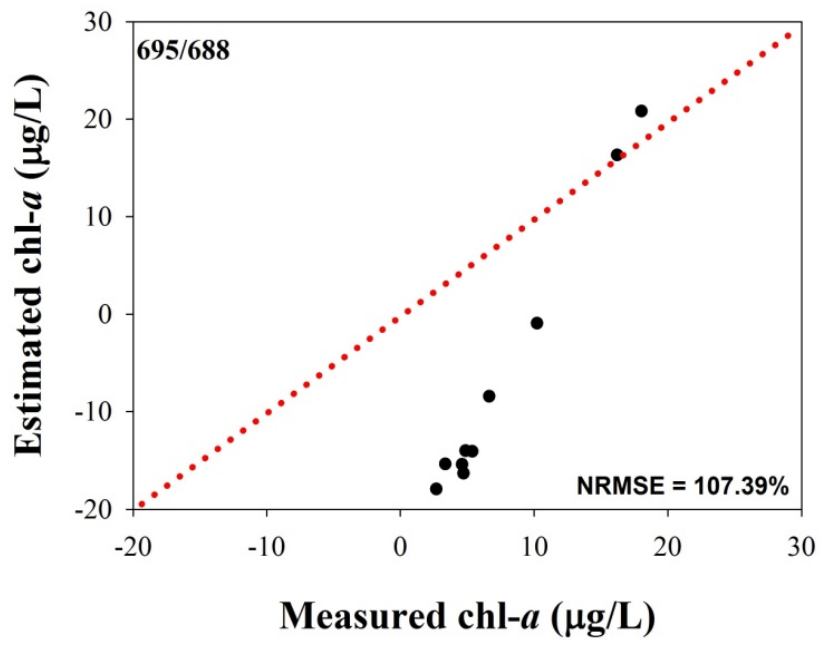

$\cdots \cdot 1: 1$

\section{Conclusions}

In this article, we presented an open access statistical web tool for data collinearity analysis, which will support mainly remote sensing research. The ICE presented a good performance on time processing of different datasets and it used only the resources of the personal browser and not the resources from the client machine or a server. From the four web browsers analyzed in this research, 
Mozilla Firefox produced the best performance based on the processing time and ability to process all test datasets. The ICE also presented several functions, which improve the visualization of the 2D correlation plot that was easily generated from a friendly interface platform.

The use of ICE for bio-optical modeling is recommended because it considers the environment's optical characteristics, which vary due to the concentration of optically active constituents. As shown in this study, the ICE's band ratio selections were useful for bio-optical modeling of different biogeochemical variables. As shown in Table 3, calibration of ICE's band ratios produced the highest $\mathrm{R}^{2}$ for each dataset, all of them with an $\mathrm{R}^{2}$ over 0.95 . Therefore, the $\mathrm{R}^{2}$ values for FM12, FS12, and FA13 were 0.992, 0.976, and 0.957, respectively. Compared to the two Red-NIR band ratios described in the literature, calibrations using ICE showed better results.

The validation of the cross-calibration processes among the three datasets were shown in Table 4, which also demonstrated that the use of ICE improved the chl- $a$ concentration estimation. Scatter plots from the best (Figure 7) and the worst (Figure 8) validations, based on the NRMSE values, also confirm that the use of ICE improved the estimation of chl- $a$ concentration. Thus, the web tool may assist the determination of rock and soil constituents, as well as identify the biogeochemical components of a leaf and water.

As new hyperspectral sensors such as Environmental Mapping and Analysis Program (EnMAP), Hyperspectral Infrared Imager (HyspIRI) and PRecursore IperSpettrale della Missione Applicativa (PRISMA) are being developed to improve hyperspectral measures from space, a tool, such as ICE, will be crucial to support statistical analysis of several future studies including biogeochemical research. Therefore, the development of web tools will enhance spectral research due to its practicability to conduct the analysis. This article also invites the scientific community to test and give us your feedback about ICE in order to improve it for future versions.

\section{Acknowledgments}

This work was supported by grant 2011/19523-8, São Paulo Research Foundation (FAPESP) and grant 471223/2011-5, National Council for Research and Development (CNPq). We also want to thank FURNAS and Remote Sensing Post Graduation Course (PG-SER) for supporting field trip and analysis. I.O and P.B.A.S. thank Coordination for the Improvement of Higher Education Personnel (CAPES) for the scholarships. M.P.C. is grateful to the CNPq for the doctorate scholarship (under grants 161233/2013-9).

\section{Author Contributions}

Igor Ogashawara is the main author who performed the analyses and wrote the paper with contributions from all the authors. Marcelo P. Curtarelli developed the mathematical routine for the plotting of correlations. Arley F. Souza implemented ICE as a webtool. Pétala B. Augusto-Silva collected the data from Funil Reservoir. Enner H. Alcântara and José L. Stech designed the research as well as provided funding for the field trips. 


\section{Conflicts of Interest}

The authors declare no conflict of interest.

\section{References and Notes}

1. Mitra, D.; Samant, G.; Sengupta, K. Correlogram-based method for comparing biological sequences. Lect. Notes Comput. Sci. 2006, 4031, 953-961.

2. Melton, M.A. Methods for measuring the effect of environmental factors on channel properties. Geophys. Res. Lett. 1962, 67, 1485-1490.

3. Atzberger, C.; Guérif, M.; Baret, F.; Werner, W. Comparative analysis of three chemometric techniques for the spectroradiometric assessment of canopy chlorophyll content in winter wheat. Comput. Electron. Agric. 2010, 73, 165-173.

4. Song, K.; Li, L.; Tedesco, L.P.; Li, S.; Duan, H.; Liu, D.; Hall, B.E.; Du, J.; Li, Z.; Shi, K.; Zhao, Y. Remote estimation of chlorophyll-a in turbid inland waters: Three-band model versus GA-PLS model. Remote Sens. Environ. 2013, 136, 342-357.

5. Song, K.; Li, L.; Li, Z.; Tedesco, L.; Hall, B.; Shi, K. Remote detection of cyanobacteria through phycocyanin for water supply source using three-band model. Ecol. Inform. 2013, 15, 22-33.

6. Zhang, T.-T.; Zeng, S.-L.; Gao, Y.; Ouyang, Z.-T.; Li, B.; Fang, C.-M.; Zhao, B. Using hyperspectral vegetation indices as a proxy to monitor soil salinity. Ecol. Indic. 2011, 11, 1552-1562.

7. Farifteha, J.; Meer, F.V.; Atzberger, C.; Carranza, E.J.M. Quantitative analysis of salt-affected soil reflectance spectra: A comparison of two adaptive methods (PLSR and ANN). Remote Sens. Environ. 2007, 110, 59-78.

8. Hansen, P.M.; Schjoerring, J.K. Reflectance measurement of canopy biomass and nitrogen status in wheat crops using normalized difference vegetation indices and partial least squares regression. Remote Sens. Environ. 2003, 86, 542-553.

9. Vincent, R.K.; Qin, X.M.; McKay, R.M.L.; Miner, J.; Czajkowski, K.; Savino, J.; Bridgeman, T. Phycocyanin detection from Landsat TM data for mapping cyanobacterial blooms in Lake Erie. Remote Sens. Environ. 2004, 89, 381-392.

10. Oki, K. Why is the ratio of reflectivity effective for chlorophyll estimation in the lake water? Remote Sens. 2010, 2, 1722-1730.

11. Ha, N.T.T.; Koike, K.; Nhuan, M.T. Improved accuracy of chlorophyll-a concentration estimates from MODIS imagery using a two-band ratio algorithm and geostatistics: As applied to the monitoring of eutrophication processes over Tien Yen Bay (Northern Vietnam). Remote Sens. 2014, 6, 421-442.

12. Gitelson, A.A.; Dall'Olmo, G.; Moses, W.J.; Rundquist, D.C.; Barrow, T.; Fisher, T.R.; Gurlin, D.; Holz, J. A simple semi-analytical model for remote estimation of chlorophyll-a in turbid waters: Validation. Remote Sens. Environ. 2008, 112, 3582-3593.

13. Ogashawara, I.; Mishra, D.R.; Mishra, S.; Curtarelli, M.P.; Stech, J.L. A performance review of reflectance based algorithms for predicting phycocyanin concentrations in inland waters. Remote Sens. 2013, 5, 4774-4798. 
14. Schalles, J.F.; Yacobi, Y.Z. Remote detection and seasonal patterns of phycocyanin, carotenoid, and chlorophyll pigments in eutrophic waters. Arch. Hydrobiol. 2000, 55, 153-168.

15. Simis, S.G.H.; Peters, S.W.M.; Gons, H.J. Remote sensing of the cyanobacterial pigment phycocyanin in turbid inland water. Limnol. Oceanogr. 2005, 50, 237-245.

16. Mishra, S.; Mishra, D.R.; Schluchter, W.M. A novel algorithm for predicting phycocyanin concentrations in cyanobacteria: A proximal hyperspectral remote sensing approach. Remote Sens. 2009, 1, 758-775.

17. O'Connor, G.C.; O'Keefe, B. Viewing the web as a marketplace: The case of small companies. Decis. Support Syst. 1997, 21, 171-183.

18. Power, D.J. Decision Support Systems: Concepts and Resources for Managers; Quorum Books: Westport, CT, USA, 2002.

19. Delen, D.; Sharda, R.; Kumar, P. Movie forecast Guru: A web-based DSS for Hollywood managers. Decis. Support Syst. 2007, 43, 1151-1170.

20. Rocha, M.I.A.; Branco, C.W.C.; Sampaio, G.F.; Gômara, G.A.; Filippo, R. Spatial and temporal variation of limnological features, Microcystis aeruginosa and zooplankton in a eutrophic reservoir (Funil Reservoir, Rio de Janeiro). Acta Limnol. Bras. 2002, 14, 73-86.

21. Branco, C.W.C.; Rocha, M.I.A.; Pinto, G.F.S.; Gômara, G.A.; Filippo, R. Limnological features of Funil Reservoir (R.J., Brazil) and indicator properties of rotifers and cladocerans of the zooplankton community. Lakes Reserv. Res. Manag. 2002, 7, 87-92.

22. Primo, A.R.R. Avaliação da Influência do Reservatório de Funil na Qualidade da Água do rio Paraíba do Sul. Master Thesis, Universidade de São Paulo, São Paulo, Brazil, 2006.

23. Ferrão-Filho, A.S.; Soares, M.C.; Rocha, M.I.A.; Magalhães, V.F.; Azevedo, S.M.F.O. Florações de Cianobactérias tóxicas no Reservatório do Funil: Dinâmica sazonal e consequências para o zooplâncton. Oecologia Bras. 2009, 13, 346-365.

24. Nush, E.A. Comparison of different methods for chlorophyll and phaeopigment determination. Arch. Hydrobiol. Beih. Ergebn. Limnol. 1980, 14, 14-36.

25. Lorenzen, C.J. Determination of chlorophyll and pheo-pigments: Spectrophotometric equations. Limnol. Oceanogr. 1967, 12, 343-346.

26. Moses, W.J.; Gitelson, A.A.; Berdnikov, S.; Povazhnyy, V. Estimation of chlorophyll-a concentration in case II waters using MODIS and MERIS data-Successes and challenges. Environ. Res. Lett. 2009, 4, 1-8.

(C) 2014 by the authors; licensee MDPI, Basel, Switzerland. This article is an open access article distributed under the terms and conditions of the Creative Commons Attribution license (http://creativecommons.org/licenses/by/3.0/). 